\title{
Mechanisms of renal tubular defects in old age
}

\author{
A. S. Dontas \\ M.D. (Athens), M.Sc. (Michigan) \\ M.D. (Athens) \\ P. Papanayiotou \\ M.D. (Athens) \\ Department of Clinical Therapeutics, \\ University of Athens, and Centre of Studies of Age-related Changes \\ in Man, Athens, Greece
}

S. G. Marketos

\begin{abstract}
Summary
The mechanisms of renal tubular dysfunction in old age have been examined in twenty-eight clinically healthy elderly subjects without infection, and in fourteen subjects of similar age with laboratory evidence of intrarenal infection. The data were compared with those from thirteen clinically healthy young subjects. Studied were: proximal tubular ( $\mathbf{T m}_{\mathrm{PAH}}$ ) and distal tubular $\left(\mathrm{C}_{2} \mathrm{O}\right)$ activity, minimal and maximal osmolal U/P ratios, maximal osmolal excretion in hydropenia, and GFR levels under standard hydration and under water-loading.

The reduction of GFR in old age is evident particularly in men under conditions of standard hydration: it is accentuated in the presence of renal infection. Proximal tubular activity is also significantly lower in elderly men, especially if they have chronic bacteriuria. The reduction is closely related to GFR levels, with identical $T m_{P A H}: C_{\text {in }}$ ratios in all groups. This supports the intact nephron hypothesis for this part of the nephron. Distal tubular activity is depressed in old age in both sexes proportionately more than proximal tubular activity or the GFR. The lower $\mathrm{CH}_{2} \mathrm{O}$ : GFR ratios imply a selective distal tubular damage.

Maximal osmolal $\mathbf{U} / \mathbf{P}$ ratios in hydropenia are significantly higher in the young (mean 3.67) than in either the elderly non-infected (mean $2 \cdot 79$ ) or the elderly infected subjects (mean 2.12). Conversely, minimal $U / P$ ratios in water-loading are lower in the young (mean 0.247) than in either elderly group (means 0.418 and 0.668). Osmolal excretion in hydropenia is not different between the groups, but urine flows in water-loading clearly separate them.

The data indicate that simple functions of the

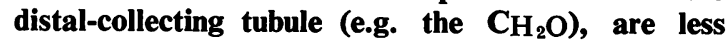
affected in old age than are functions involving several medullary structures (as is the maximal $U_{\text {osm }}$ or $\mathrm{U} / \mathrm{P}$ ratio). They suggest that the main impairment of the distal tubular cell involves the failure to achieve a proper osmotic gradient between tubular fluid and
\end{abstract}

blood, rather than an inability to excrete or re-absorb an adequate amount of solute. Finally, it appears that renal infection aggravates the larger glomerular and proximal tubular deficits observed in non-infected men: it depresses distal tubular function equally in both sexes.

\section{Introduction}

Reduction of maximal urinary concentrating capacity in old age is a well-recognized phenomenon (Miller \& Shock 1953; Tassinari \& Pin, 1958; Lindeman et al., 1960). The mechanisms responsible for this tubular dysfunction are not completely clarified and include an increased solute and water load per functioning nephron (Bricker, 1961), reduced efficiency of individual nephrons (Davies \& Shock, 1950; Miller \& Shock, 1953; Adams \& Barrows, 1963), and alterations in the inner medulla resulting in reduced hypertonicity (Lindeman et al., 1966).

We have previously demonstrated that in elderly subjects tubular function is reduced proportionately to the levels of glomerular filtration rate (GFR) and renal plasma flow (RPF), and that the presence of renal infection produces tubular damage beyond that attributable to age alone (Dontas et al., 1968). Dilution-impairment in old age has not been demonstrated, and in most forms of chronic renal disease diluting ability is retained long after significant losses of concentrating ability are obvious.

The decreased concentrating power during hydropenia might be related either to an inability of the distal nephron to generate a maximal osmolal concentration difference between blood and terminal tubular fluid (a gradient impairment) or to an inability to excrete a maximal amount of solute per unit of volume of urine (a capacity impairment). Conversely, if diluting defects of the aged kidney exist, these can be related either to a distal and collecting tubular cell inability to lower the minimal urine concentration with respect to plasma (gradient im- 
pairment), or to an inadequacy of solute reabsorption independently of water, i.e. reduced formation of electrolyte-free water (capacity impairment).

In the present paper the following questions were investigated in order to clarify the mechanisms of renal tubular defects in old age and their modification by renal infection:

(1) Is only urinary concentration impaired in old age or also dilution ability?

(2) Does the impairment of tubular function indicate a gradient or a capacity defect?

(3) Are proximal and distal tubular functions affected to the same extent or not?

(4) How does intrarenal infection modify these functional defects?

\section{Subjects}

The subjects belonged to two age groups: $(a)$ forty-two elderly ambulant residents of the Home for the Aged (sixteen males, twenty-six females, mean age $79.4 \pm 3.6$ years), with no evidence of clinically active renal disease, and without calculus nephropathy, cardiac decompensation, or diabetes mellitus. They were consuming the standard diet of the Home, which at the time of these studies included $70-80 \mathrm{~g}$ of protein and $5.0 \mathrm{~g}$ of salt daily. These subjects were divided into two groups, depending on the presence of persistent bacteriuria form the upper urinary tract: fourteen subjects with repeatedly positive cultures during the 2 years immediately prior to the study, composed the infected' group, and twenty-eight subjects with consistently negative cultures composed the 'noninfected' group. Individuals with doubtful, intermittent, or bladder bacteriuria were excluded from this series. There was no age difference between the male (mean age 79.9 years) and the female (mean age $79 \cdot 2$ years) subjects. Similarly there were six hypertensives $(>160 / 90 \mathrm{mmHg}$ ) in the infected group and nine in the non-infected group.

In addition, thirteen young and healthy volunteers (eleven males, two females, mean age $24 \cdot 2$ ), residing in their homes and consuming a diet containing $100-120 \mathrm{~g}$ of protein daily, were also studied for comparison purposes.

Several urine cultures were performed on each subject. The first two or three screening cultures were obtained by a specially trained nurse before the clearance study, and the last one following it from cleanly voided morning midstream specimens. Several cultures were also obtained during bladder catheterization for the clearance studies. Only subjects with positive cultures from fresh ureteral urine, following emptying and thorough cleansing of the bladder with saline, and whose urines remained positive throughout the clearance test were termed 'infected'. Also, only subjects with consistently negative cultures were termed 'non-infected'. All samples were examined within $4 \mathrm{hr}$ of collection, during which period the specimens were kept at $4^{\circ} \mathrm{C}$. Counts were obtained in all specimens by a quantitative pour-plate method (Cruickshank, 1965), after incubation for a minimum of $24 \mathrm{hr}$ at $37^{\circ} \mathrm{C}$ in blood agar and in McConkey's agar. Subcultures were made in nutrient broth and biological tests were used to identify bacteria when present in numbers exceeding $100,000 / \mathrm{ml}$. The bacterial species isolated were: Escherichia coli, eight; Paracolon bacteria, one; Citrobacter, one; Pseudomonas aeruginosa, one; Klebsiella pneumoniae, one; mixed organisms, two.

\section{Methods}

Each subject, in addition to the tests described below, had frequent clinical and routine laboratory examinations. The nature and objects of this study were outlined to every subject, most of whom cooperated willingly for the entire investigation period. A few drop-outs are indicated by the smaller number of subjects in the water-loading test. The tests were conducted over a 6-8 month period, as follows:

(a) Evaluation of proximal tubular activity and standard glomerular filtration rate

These functions were determined simultaneously in the spring of 1969 by the maximal transport rate of PAH (TmPAH), and the clearances of inulin and creatinine $\left(\mathrm{C}_{\mathrm{in}}, \mathrm{C}_{\text {creat }}\right)$, according to classical procedures, in which urine flows averaged $4-6 \mathrm{ml} / \mathrm{min}$. All clearance and $T_{m}$ values reported are corrected to a $1.73 \mathrm{~m}^{2}$ surface area.

\section{(b) Evaluation of distal tubular activity and glomerular filtration rate in water-loading}

These functions were determined by the simultaneous clearances of 'free water' $\left(\mathrm{C}^{\prime} \mathrm{H}_{2} \mathrm{O}\right)$ and creatinine (and inulin in most cases) in the winter months of 1969-70, on as many of the subjects as above as possible. Administration of $5-10 \mathrm{ml} / \mathrm{kg}$ of tap water orally was followed by a rapid infusion of $2-2.51$ of a mixture of normal saline and $5 \%$ glucose in water. The infusion was administered over a period of 90-120 min, but it was interrupted earlier if a maximal steady urine flow had been obtained. As the mean weight of the elderly subjects was $15 \%$ below that of the young ones, the average elderly subject was relatively overhydrated during this test compared with the young subjects. Five subjects with heart disease were previously digitalized, so that they did not exhibit any side-effects, except one who was excluded from this series.

(c) Evaluation of maximal and minimal osmolal U/P ratios, and of maximal $U \times V$ values in hydropenia

An overnight test of hydropenia was performed as described previously (Dontas et al., 1968) during the 
summer months of 1969 , i.e. after the standard clearance study (a) and before the water-loading test (b) on the same subjects. Volume and osmolality of several samples of freely voided night urine, as well as evening and morning plasma osmolalities were determined. Maximal osmolal $U / P$ ratios and $U \times V$ values were computed from these data.

Minimal osmolal $U / P$ ratios were determined during the water-loading test as above (b), urine samples being obtained every 3-5 min through the bladder catheter.

All clearance tests were performed in the recumbent state in the morning, after fasting for $12 \mathrm{hr}$. The bladder was emptied by catheterization and washouts followed by air. Strict aseptic measures were followed throughout all clearance tests and at the end of each catheterization $1 \mathrm{~g}$ of chloramphenicol was instilled into the bladder. Thus, no evidence of bladder infection became apparent in any subject following these tests. Inulin, endogenous creatinine and sodium paraaminohippurate were determined by standard techniques, previously described (Dontas et al., 1968). Plasma and urine osmolality were estimated by determination of the freezing point in a Precision Systems Osmette, and are expressed as milliOsmols/ $\mathrm{kg}$ of water.

Statistical evaluation of the data was done by comparing the various subgroups with the $t$-test, as routinely performed in all such studies. This assumes that: (1) the individual values are normally distributed, and (2) that the kidney variables studied are independent of one another. Some of the functions reported are in reality interdependent (e.g. max $\mathrm{U}_{\text {osm }}$ and osmolal $\mathrm{U} / \mathrm{P}$ ratios), the majority, however, are not $\left(\mathrm{C}_{\mathrm{in}}, \mathrm{U} / \mathrm{P}\right.$ ratios and $\left.\mathrm{Tm}_{\mathrm{PAH}}\right)$ and, in any case, comparison was carried out within rows in each test.

\section{Results}

The data are reported in detail in Tables 1 and 2, and some results are indicated in Figs. 1-4. It may be noted that values of GFR in general are smaller in hydropenia (Table 1) than in the water-loading test (Table 2). Actually, as indicated in the section on methods, the values of $C_{i n}$ in 'hydropenia' were obtained some weeks earlier, during a standard clearance procedure. During these tests, urine flows were much below the flows obtained during water loading in which the respective $C_{\text {in }}$ and $C_{\text {creat }}$ levels in Table 2 were determined.

Further in 'hydropenia' the elderly males have significantly reduced GFR levels this being particularly evident in the infected subjects (Table 1). Sex differences in $C_{i n}$ and $C_{c 1 \text { eat }}$ of the non-infected subjects are eliminated when these tests are determined during water loading (Table 2), presumably because of equal renal mass expansion. GFR values of the infected group (particularly males), although higher in water-loading than in hydropenia, are still significantly below those of the non-infected group.

\section{Proximal and distal tubular activity}

Both $\mathrm{Tm}_{\mathrm{PAH}}$ and $\mathrm{C}_{\mathrm{H}_{2} \mathrm{O}}$ are significantly decreased in old age and more severely so in the presence of infection. The male infected subjects in particular, exhibit significantly lower values, when compared either with infected females or with non-infected males. The mean TmPaH levels of the non-infected and infected males average $66 \%$ and $45 \%$ respectively of those of the young healthy subjects; the corresponding levels for $\mathrm{C}_{\mathrm{H}_{2} \mathrm{O}}$ are $57 \%$ and $28 \%$.

Despite these reductions in absolute levels of proximal and distal tubular activity of elderly males, the relative proximal tubular : glomerular ratio $\left(\mathrm{Tm}_{\mathrm{PAH}} / \mathrm{C}_{\mathrm{in}}\right)$ is found to be equal in both sexes and all groups. It is interesting that individual $\mathrm{Tm}_{\mathbf{P A H}}$ and $\mathrm{Tm}_{\mathrm{PAH}} / \mathrm{C}_{\mathrm{in}}$ values in both elderly groups (Fig. 1 , Table 1) have a wider scatter.

In contrast to the relative proximal, the relative distal tubular activity is less well preserved, the $\mathrm{C}_{\mathrm{H}_{2} \mathrm{O}} / \mathrm{C}_{\text {creat }}$ ratio being significantly lower in either group of elderly subjects compared with the young ones. The more pronounced decrease in the mean ratios of $\mathrm{C}_{\mathrm{H}_{2} \mathrm{O}} / \mathrm{C}_{\text {in }}$ and $\mathrm{C}_{\mathrm{H}_{2} \mathrm{O}} / \mathrm{C}_{\text {creat }}$ in the infected group (Fig. 2, Table 2) is not significant, because of the greater variance in this group caused by the 'negative' value of $\mathrm{C}_{\mathrm{H}_{2} \mathrm{O}}$ in one bacteriuric male subject under water load.

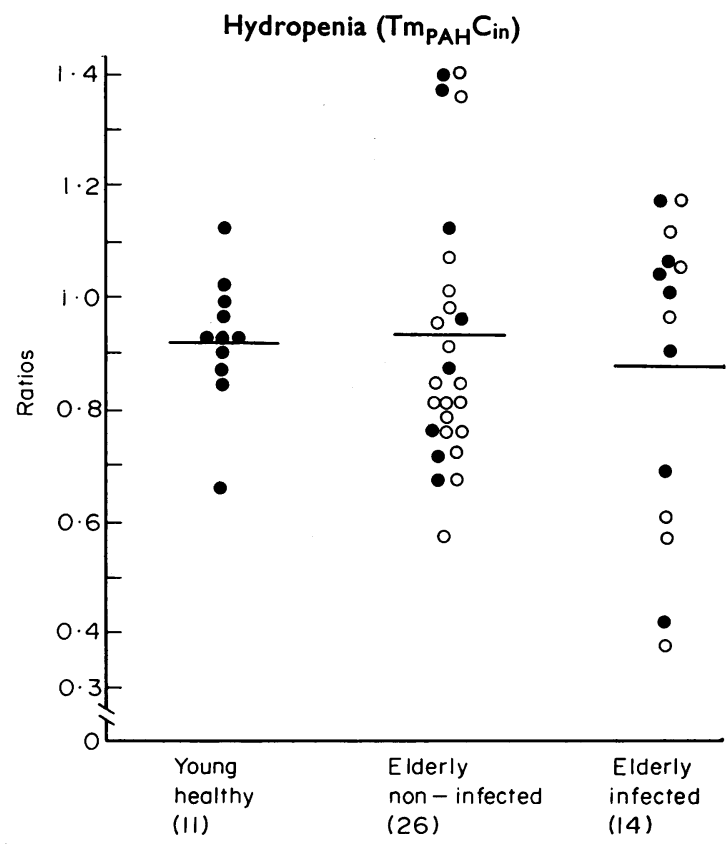

Fig. 1. Ratios $\mathrm{Tm}_{\mathrm{PAH}} / \mathrm{C}_{\text {in }}$ in the three groups. Males; $O$, females. 


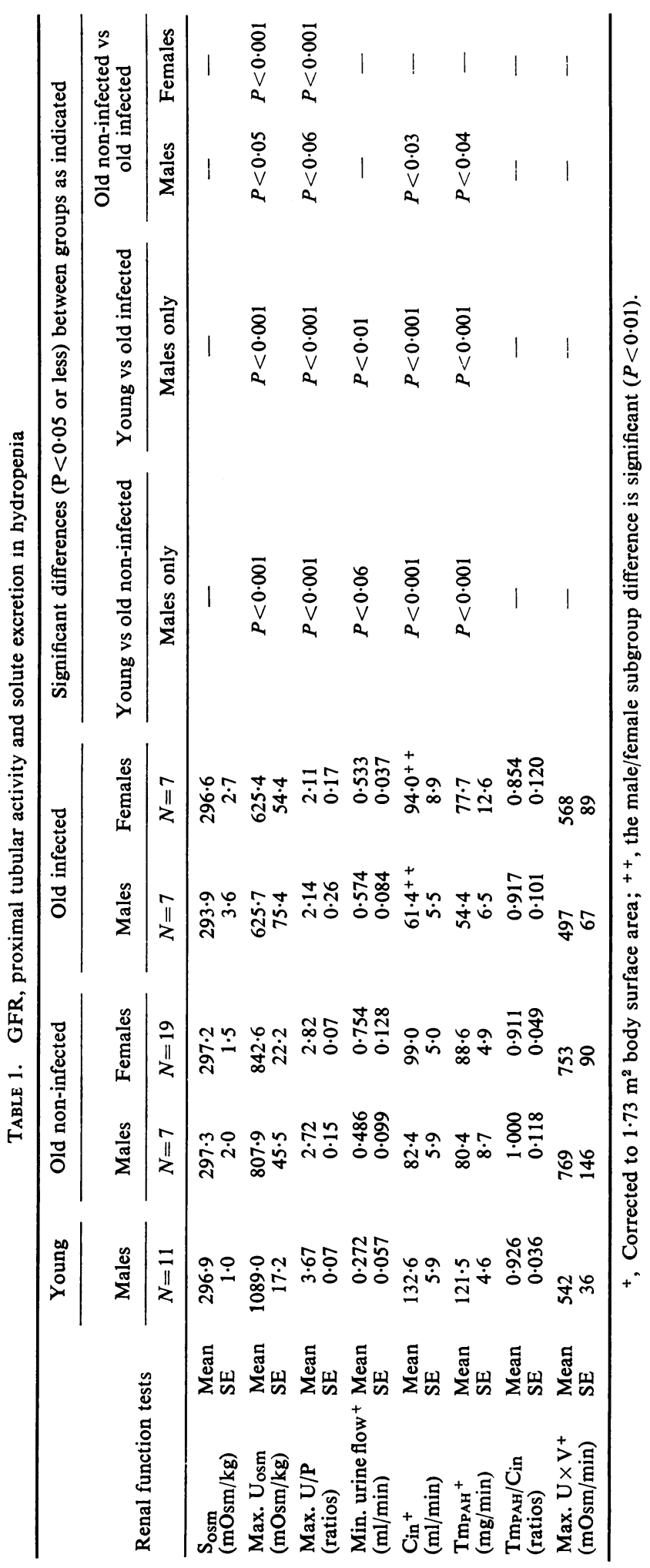




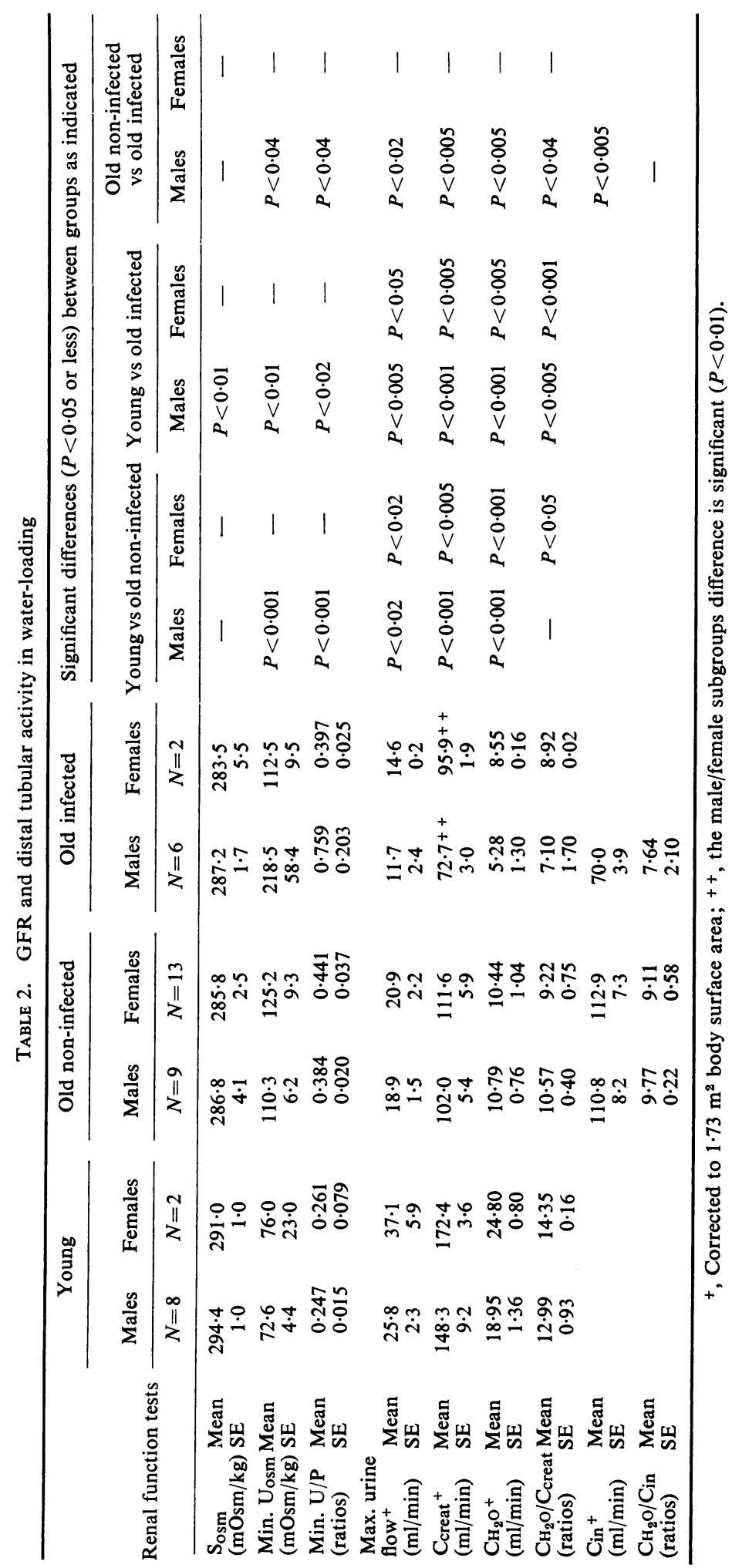




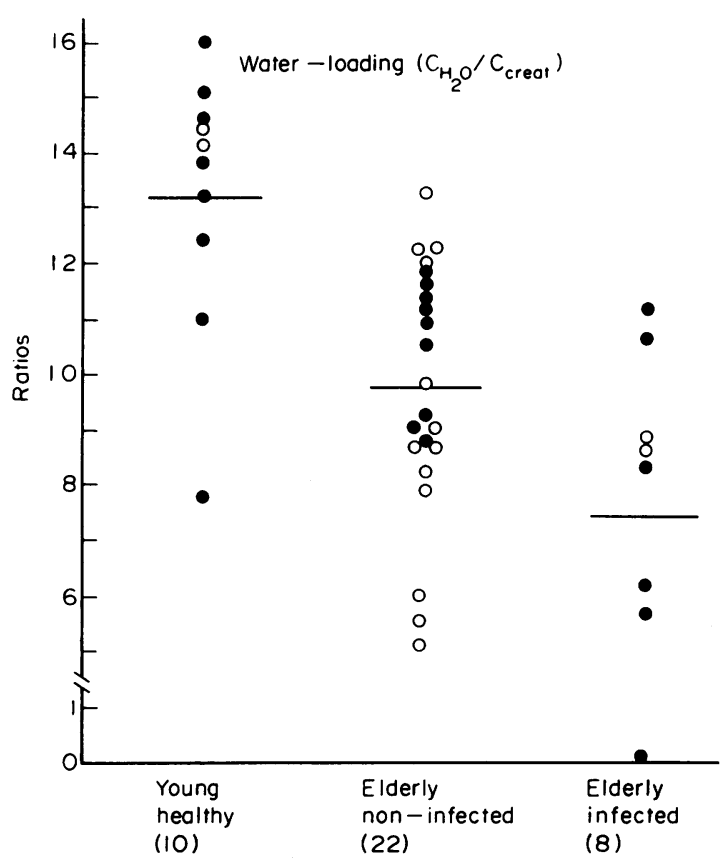

Fig. 2. Ratios $\mathrm{CH}_{2} \mathrm{O} / \mathrm{C}_{\text {creat }}$ in the three groups. Males; $\mathbf{O}$, females.

\section{Maximal and minimal osmotic $U / P$ ratios}

The maximal urine osmolality as well as the maximal $\mathbf{U} / \mathbf{P}$ ratio in hydropenia are significantly lower in the elderly infected group compared with the non-infected, and in the latter group compared with the young group (Table 1, Fig. 3). Similarly, the mean minimal osmolal $\mathrm{U} / \mathrm{P}$ ratio in water-loading is significantly higher in both elderly groups compared with the young subjects. The difference in mean minimal U/P ratios between the two elderly groups is not significant (Fig. 4).

\section{Osmolal excretion in hydropenia}

The maximal osmolal excretion in hydropenia ( $\max . \mathrm{U} \times \mathrm{V}$ ) is higher (not significantly) in the noninfected elderly compared with either the infected elderly or the young group. The lower osmolal excretion in the latter group results from the significantly lower urine flow levels of the young subjects in the test of hydropenia (Table 1).

\section{Urine flow in water-loading}

Maximal urine flows under water-loading are significantly higher in the young subjects than in the elderly non-infected, and in turn in the latter compared with the old infected (Table 2). The relatively large urine flows combined with high $U_{\text {osm }}$ resulted in generally lower $S_{\text {osm }}$ in this test in the older groups, which is significant in one comparison. Peak

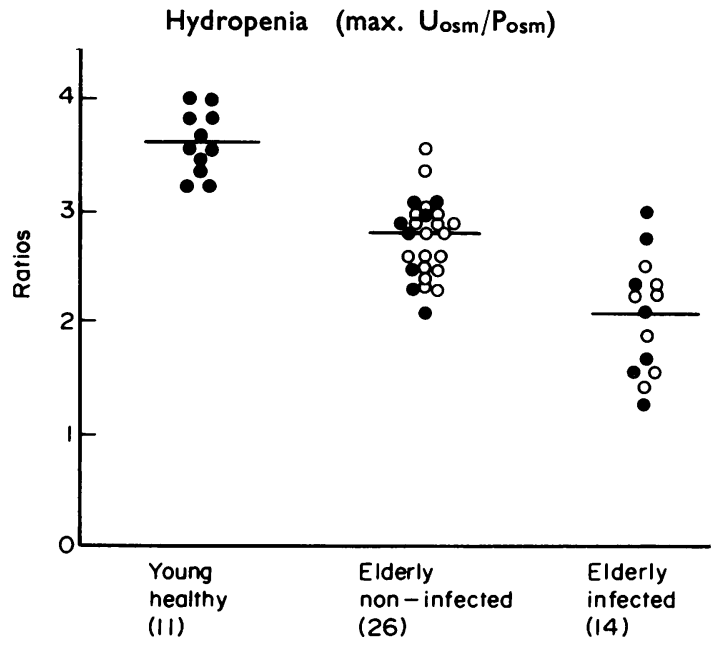

FIG. 3. Ratios max. Uosm/Posm in the three groups. , Males; O, females.

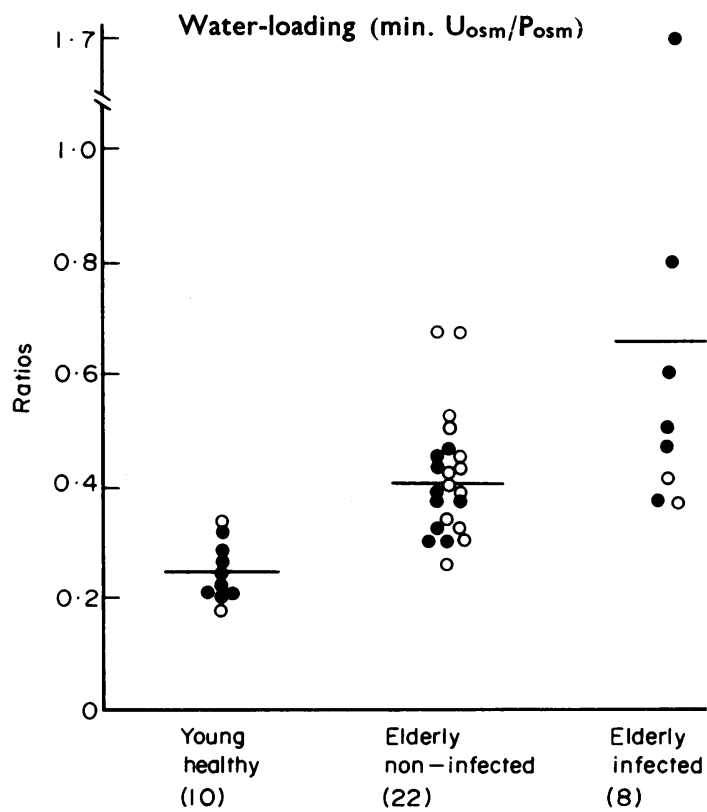

Fig. 4. Ratios min. Uosm/Posm in the three groups. , Males; O, females.

flow rates during the water-loading test were reached somewhat earlier after the start of the infusion in the young group (mean $77 \mathrm{~min}$ ), than in either of the elderly groups ( $95 \mathrm{~min}$ in either group), although the rate of fluid administration did not differ between the three groups. 


\section{Discussion}

The results of the present studies indicate that: (1) urinary dilution is much less affected than is the more complex function of urine concentration; (2) the defect of the distal nephron indicates an inability to generate a maximal solute gradient between blood and tubular fluid; (3) proximal tubular activity is also reduced in old age but retains a constant ratio to GFR ; and, (4) intrarenal infection further aggravates all renal functions in the male subjects, but only distal tubular activity in the elderly females.

(1) During the past decade various comprehensive studies investigating the diluting capacity of the hypertensive or senile human kidney have yielded conflicting results. Cannon (1968) and Buckalew et al. (1969) have shown decreases of $\mathrm{C}_{\mathrm{H}_{2} \mathrm{O}}$ per unit of urine flow or GFR in essential hypertensives given intravenous isotonic glucose or hypotonic saline, which data imply impaired sodium re-absorption in the 'distal' nephron. On the other hand, Steinmetz et al. (1964) found no abnormality in $\mathrm{C}_{\mathrm{H}_{2} \mathrm{O}}$ during mannitol diuresis in hydrated hypertensives, and Metzger et al. (1967) reported values of $\mathrm{C}_{\mathrm{H}_{2} \mathrm{O}} / \mathrm{GFR}$, at comparable Cosm higher in hypertensives than in normotensives during oral water loads. In elderly subjects Lindeman et al. (1966) have shown significant reductions in $\mathrm{C}_{\mathrm{H}_{2} \mathrm{O}}$ under oral water and parenteral isotonic glucose loads leading to maximal diuresis levels much below our own. Despite reductions in $\mathrm{C}_{\mathrm{H}_{2} \mathrm{O}}$, the normal renal responses to infused antidiuretic hormone in their subjects indicated unimpaired distal tubular cell activity in old age, even in the pyelonephritic patients studied. Variations in the extent of extracellular fluid volume expansion, in composition and osmolality of infusions, and in basal renal haemodynamics may account for the different responses obtained by the above authors.

The data reported herein show a moderate but significant decrease in $\mathrm{C}_{\mathrm{H}_{2} \mathrm{O}}$ per unit of GFR in both groups of elderly subjects (Fig. 2). This reduction, occurring under relatively heavier hydration than that of the young controls or of the subjects in most other reports, indicates that a moderate distal tubular absorptive defect in old age does exist. This conclusion is justified by extensive experimental data which have demonstrated that expansion of extracellular fluid volume orally by water, or by intravenous hypotonic or isotonic saline, is followed by increases in $\mathrm{C}_{\mathrm{H}_{2} \mathrm{O}}$ as a result of augmented solute delivery from proximal to distal nephronal sites (Eknoyan et al., 1967; Hayslett, Kashgarian \& Epstein, 1967; Stein et al., 1967). Further, it is well established that although minimal urine osmolality may be elevated in advanced renal disease this is due to increased solute diuresis per nephron, and the $\mathrm{C}_{\mathrm{H}_{2} \mathrm{O}}$ is not reduced (Bricker, 1961, 1969; Morrin et al., 1970; Ofstad, Gjersvik \& Kolsaker, 1968).
The inability to excrete free water observed in one infected subject in our study suggests that in addition to the mild damage common to all elderly subjects, there exists a more selective distal tubular impairment in occasional individuals with advanced renal infection (Sommers et al., 1964).

A number of different factors contribute to the effectiveness of urine concentration, failure in any one of which reduces the adequacy of the process; it is not surprising, therefore, that defects in concentrating capacity in old age have been reported for over 30 years (Lewis \& Alving, 1938). As expected, a significant decrease of $U_{\max }$ as well as in maximal $\mathbf{U} / \mathbf{P}$ osmolal ratios was observed in both elderly groups (Table 1), this being significantly more pronounced in the group with renal infection (Fig. 3). Among the physiological mechanisms involved in this difference the influence of moderate habitual protein and salt ingestion as against that of average underhydration of the old subjects has to be considered. The extent by which the opposing effects of these factors may have reduced maximal concentration ceilings is debatable. However, a mean maximal $\mathrm{U} / \mathrm{P}$ ratio of 2.77 was obtained by Boyarsky \& Smith (1957) in middle-aged subjects subsisting on a 'ward' diet, and the maximal $U_{\text {osm }}$ of normal young men studied by Epstein et al. (1957) after 3 days on $150-200 \mathrm{~g}$ protein intake averaged $960 \mathrm{mOsm} / \mathrm{kg}$. These data indicate that the maximal urine osmolalities in the present study were related to age changes and were not affected by restrictions in protein intake.

A more important mechanism involved in the decrease in maximal urine osmolality in old age is probably the fall of GFR and the consequent prolongation of contact of the filtrate with salt-absorbing tubules. An average decrease of $37 \%$ in $\mathrm{C}_{\text {in }}$ between young males and non-infected aged males is accompanied by a $26 \%$ reduction in maximal $\mathrm{U}_{\text {osm. }}$. This is in agreement with acute observations on hydropenic subjects on normal or salt-free diets (Levitt, Levy \& Polimeros, 1959). The additional significant drop in $U_{\text {osm }}$ in bacteriuria, equal in infected males and females, can not be related to the progressive reductions in GFR (Brod, 1971) which occurred only in the infected males. Therefore, the effect of bacteriuria on concentration, appears as separate from and additive to that of lowered GFR. These results confirm our previous studies (Dontas et al., 1966, 1968) that bacteriuria is an independent, significant factor in the decrease of maximal concentrating ability in old age. They further point out that its importance equals that of uncomplicated age and moderate protein intake combined (Fig. 3) (Shock, 1952; Epstein et al., 1957).

(2) The renal functions examined (Tables 1 and 2) indicate that the tests of osmolal gradient, i.e. 
maximal and minimal osmotic $\mathrm{U} / \mathrm{P}$ ratios and absolute $U_{\text {osm }}$ values (Figs. 3 and 4), exhibit larger impairments in old age than do tests of maximal excretory (Fig. 1) or absorptive (Fig. 2) tubular capacity when factored by GFR. Since the mechanisms involved are closely similar to those regulating salt conservation in advanced renal disease (Coleman et al., 1966), the present data support the view that the infected and/or sclerotic kidney in hydropenia is unable to elevate the urine osmolality above a fixed, relatively low value. Conversely, in overhydration the diseased kidney is restricted in its attempt to lower the urine osmolality below a relatively high ceiling. It should be noted that whenever solute excretion at low urine flows is studied, as in the concentration test herein, the concentration ceiling and the very low flows prevailing do not permit an adequate discrimination between the groups.

Overlaps between the three groups studied exist nevertheless even in the better delineated functions, such as the maximal U/P ratio (Fig. 3 ). To differentiate more clearly the three groups either additional physiological stresses must be imposed upon the kidney or functions studied which depend upon the interplay of renal and extrarenal factors. Thus, the increase of urine flow in response to a sudden expansion of extracellular fluid volume differentiates the three groups as well and much more simply than any of the purely 'renal' tests studied (Table 2).

(3) The relationships between proximal tubular and glomerular functions examined by the ratios of Tm $\mathrm{maH}_{\text {PaH }}$ to $\mathrm{C}_{\text {in }}$ (Fig. 1) confirm our previous studies and those of others, that although a significant reduction of mean $\mathrm{Tm}_{\mathrm{PAH}}$ levels is present in old age. this occurs in parallel with similar changes in GFR, so that $\mathrm{Tm}_{\mathrm{PAH}}$ : $\mathrm{C}_{\text {in }}$ ratios remain constant. The more pronounced decrease of TmPAH in the bacteriuric group is not an unexpected finding; it reflects a more advanced state of nephrosclerosis and is consistent with the concept that renal infection is a contributory factor in the acceleration of renovascular disease (Marketos, Papanayiotou \& Dontas, 1969). Furthermore, although nephrosclerosis is a common characteristic of the two age groups, there is a significant difference in GFR levels between noninfected and infected subjects. The additional decrease of GFR in the latter cannot be accounted for by the asymptomatic bacteriuria, but by the acceleration of the pre-existing vascular disease by the intrarenal infection. The constancy of glomerulo-tubular balance in all three groups suggests that the effects of either age or infection on proximal tubular function, unlike those on distal tubular activity, which is selectively impaired, are exerted through mechanisms common to those limiting GFR. Alternatively, the proximal tubule is capable of adapting its function to a degree appropriate for each level of GFR (Bricker, 1969).

(4) The data reported herein indicate that the presence of intrarenal infection seriously impairs the function of all segments of the individual nephrons in the aged male, whereas it affects only the more distal segments (concentration capacity) in the affected females. It is likely that this disparity is a result of aggravation by infection of the effects of mechanical (Lapides, 1965) and hormonal factors (Welsh et al., 1942), on certain nephronal functions of the elderly male subject. In fact, significant differences in GFR and proximal tubular activity exist already between non-infected elderly males and females. Medullary functions are, in contrast, equally hampered in both sexes in uncomplicated old age; thus, the presence of renal infection by superimposing an additional factor depresses concentration and dilution in both sexes, but affects proximal tubular and glomerular functions predominantly in males.

\section{Acknowledgments}

The authors are indebted to Professor B. K. Malamos, Dr N. W. Shock and Mrs B. Kefakis for critical suggestions regarding the project and the manuscript. The project was supported by grants from the Greek Ministry of Sociab Services, the National Hellenic Research Foundation, tho Wellcome Foundation, and the American Heart Association (67-559).

\section{References}

Adams, J.R. \& Barrows, C.H. JR (1963) Effect of age on PAH accumulation by kidney slices of female rats. Journal of Gerontology, 18, 37.

BoyARSKY, S. \& SMITH, H.W. (1957) Renal concentrating operation at low urine flows. Journal of Urology, 78, 511.

BRICKER, N.S. (1961) Chronic progressive renal disease: Pathologic physiology and relation to treatment. Progress in Cardiovascular Disease, 4, 170.

BRICKER, N.S. (1969) On the meaning of the intact nephron hypothesis. American Journal of Medicine, 46, 1 .

BRoD, J. (1971) Study of renal function in the differential diagnosis of kidney disease. British Medical Journal, 3, 135.

Buckalew, V.M., Puschett, J.B. JR, Kintzel, J.E. \& GoldBerg, M. (1969) Mechanism of exaggerated natriuresis in hypertensive man; impaired sodium transport in the loop of Henle. Journal of Clinical Investigation, 48, 1007.

Cannon, P.J. (1968) Effects of five percent dextrose-water infusions in normal and hypertensive man. Circulation, $37,832$.

Coleman, A.J., Arias, M., Carter, N.W., Rector, F.C. JR \& SEldin, D.W. (1966) The mechanism of salt wastage in chronic renal disease. Journal of Clinical Investigation, 45, 1116.

Cruickshank, R. (1965) Medical Microbiology. Livingstone, Edinburgh.

Davies D.F. \& Shock N.W. (1950) Age changes in glomerular filtration rate, effective renal plasma flow, and tubular excretory capacity in adult males. Journal of Clinical Investigation, 29, 496.

Dontas, A.S., Papanayiotou, P., Marketos, S. \& EconoMOU, P. (1966) Bacteriuria in old age. Lancet, i, 305.

Dontas, A.S., Papanayiotou, P., Marketos, S.G. \& Papanicolaou, N.T. (1968) The effect of bacteriuria on renal functional patterns in old age. Clinical Science, 34, 73. 
Eknoyan, G., Suki, W.N., Rector, F.C. JR \& Seldin, D.W. (1967) Functional characteristics of the diluting segment of the dog nephron and the effect of extracellular volume expansion on its reabsorptive capacity. Journal of Clinical Investigation, 46, 1178.

Epstein, F.H., Kleeman, C.R., Pursel, S. \& Hendrickx, A. (1957) The effect of feeding protein and urea on the renal concentrating process. Journal of Clinical Investigation, $36,635$.

Hayslett, J.P., Kashgarian, M. \& Epstein, F.H. (1967) Changes in proximal and distal tubular reabsorption produced by rapid expansion of extracellular fluid. Journal of Clinical Investigation, 46, 1254.

L.APIDES, J. (1965) Role of hydrostatic pressure and distention in urinary tract infection. In: Progress in Pyelonephritis (Ed. by E. H. Kass), p. 578. Davis Co., Philadelphia.

LevitT, M.F., LeVy, M.S. \& Polimeros, D. (1959) The effect of a fall in filtration rate on solute and water excretion in hydropenic man. Journal of Clinical Investigation, 38, 463.

LewiS, W.H. JR \& Alving, A.S. (1938) Changes with age in renal function in adult men: clearance of urea; amount of urea nitrogen in blood; concentrating ability of kidneys. American Journal of Physiology, 123, 500.

Lindeman, R.D., Lee, T.D. JR, YiengST, M.J. \& Shock, N.W. (1966) Influence of age, renal disease, hypertension, diuretics, and calcium on the antidiuretic responses to suboptimal infusions of vasopressin. Journal of Laboratory and Clinical Medicine, 68, 206.

Lindeman, R.D., Van Buren, H.C. \& Raisz, L.G. (1960) Osmolar concentrating ability in healthy young men and hospitalized patients without renal disease. New England Journal of Medicine, 262, 1306.

Marketos, S.G., Papanayiotou, P. \& Dontas, A.S. (1969) Bacteriuria and non-obstructive renovascular disease in old age. Journal of Gerontology, 24, 33.
Metzger, R., Vaamonde, L., Vaamonde, C. \& Papper, S. (1967) Renal sodium excretion during oral water loading in hypertensive patients. Clinical Research, 15, 365.

Miller, J.H. \& Shock, N.W. (1953) Age differences in the renal tubular response to antidiuretic hormone. Journal of Gerontology, 8, 446.

Morrin, P.A., Joynt, M.S., Handa, S.P. \& Frame, J. (1970) The effect of uremic environment on renal concentrating and diluting mechanisms in a severely damaged nephron population. Investigative Urology, 8, 273.

OfSTAD, J., GJeRsvik, T. \& Kolsaker, L. (1968) Free water clearance in unilateral disease of the human kidney. Journal of Laboratory and Clinical Medicine, 71, 261.

SHock, N.W. (1952) Age changes in renal function. In: Cowdry's Problems of Aging (Ed. by A. L. Lansing), 3rd edn, p. 614. Williams and Wilkins, Baltimore.

Sommers, S.C., Gonick, H.C., Kalmanson, C.M. \& Guze, L.B. (1964) Pathogenesis of chronic pyelonephritis. II. Effect of repetitive infection. American Journal of Pathology, 45, 729.

Stein, R.M., Abramson, R.G., Kahn, T. \& Levitt, M.F. (1967) Effects of hypotonic saline loading in hydrated dog: evidence for a saline-induced limit on distal tubular sodium transport. Journal of Clinical Investigation, 46, 1205.

Steinmetz, R.P., Eisinger, R.P., Gombos, E.A., Chasis, H. \& BALDwIN, B.S. (1964) Excretion of free water and solute during maximal water diuresis in normal and hypertensive subjects. Journal of Laboratory and Clinical Medicine, 64, 238.

TAssinari, G. \& Pin, R. (1958) Potere di concentrazione del rene senile: risultati della prova eseguita con ormone postipofisario. Giornale di Gerontologia, 6, 19.

Welsh, C.A., Rosenthal, A., Duncan, M.T. \& Taylor, H.C. (1942) Testosterone propionate and renal function. American Journal of Physiology, 137, 338. 